\title{
REGULATIONS OF THE ASSOCIATION
}

ADOPTED 28 DEC. 1930; REVISED 21 JAN., 27 APRIL 1936, AND 10 JAN. 1938

\section{Arrearages in Membership Dues:}

If members are in arrears for dues for the preceding calendar year their copies of $P M L A$ will not be mailed to them until these dues have been paid. Members whose dues continue unpaid for eighteen months shall be dropped from the printed List of Members.

\section{Papers for the Program of the Annual Meeting:}

Members of the Association may offer papers to be read either at the General Sessions, at the Departmental Sections, or at meetings of the Discussion Groups. The titles of papers proposed for General Sessions or for the Departmental Sections should, in all cases, be accompanied by synopses (not to exceed 60 words) to be printed in the program.

Papers for General Sessions should be submitted to the Chairman of the Program Committee; papers for the Departmental Sections or Discussion Groups should be sent to the Chairman of the Section or Group concerned as announced in the March PMLA.

The latest date at which proposals for the program can be received is October 1 , but notice well in advance of this date is highly desirable as programs are usually made up before that date.

\section{Manuscripts Submitted for Publication in PMLA:}

Members have the privilege of submitting papers for publication in $P M L A$, whether these have been previously presented at the Annual Meeting or not. Manuscripts should be addressed to the Editor of $P M L A$, to be referred to the Editorial Committee. No paper shall be accepted which has not been approved by the Editorial Committee and a consultant with special competence in the field of study.

Contributors shall be allowed seventy-five cents per galley for author's corrections, but charges in excess shall be paid by the contributor.

Fifty reprints with covers (or twenty-five in the case of communications in the "Comment and Criticism" Department) will be supplied to contributors gratis. A larger number will be furnished if desired, provided that notice is given by the time corrected galley proof is returned. The cost of these extra reprints will be determined by the basis of the actual charges made by the printers.

Books: Members may submit manuscripts of books for publication in the Monograph Series, Revolving Book Fund Series, and General Series. Inquiries should be addressed to the Secretary of the Association.

Projects of Research: Information concerning, or applications for aid in, projects of research should be addressed to the Committee on Research Activities, in care of the Secretary of the Association. 